\title{
An Examination of Factors Affecting Transfer of Training among Human Resources of Iranian Medical Science Universities
}

\author{
Yaser Sayadi', Saeed Rajaeepour ${ }^{1 *}$, Yasamin Abedini' and Khalil Gholami² \\ 'Department of Educational Science, Faculty of Education and Psychology, University of Isfahan, Isfahan, Iran; \\ Yaser.Sayadi@yahoo.com, s.rajaipour@edu.ui.ac.ir,y.abedini@edu.ui.ac.ir, \\ 2Department of Educational Science, Faculty of Humanities and Social Sciences, University of Kurdistan, Kurdistan, \\ Iran; Kh.Gholami@uok.ac.ir
}

\begin{abstract}
Background/Objectives: The purpose of this study was to identify and examine the factors affecting transfer of training among human resources of Universities of Medical Science of Iran in 2015 - 2016. Methods/Statistical Analysis: Utilising a mixed method approach, this research studied a sample of 346 employees of the Universities. The research tools included a semi-structured interview and researcher-made questionnaire which its Cronbach alpha coefficient was estimated 0.93. Findings: Overall, the finding based on interviews and exploratory factor analysis (EFA) showed that employees determined six fundamental factors that affect transfer of training in Iran's Universities of Medical Science: Training design factors, Management factors, Environmental factors, Cultural factors, Supportive factors, Individual factors. Application/ Improvements: Based on the results of this study, effective training transfer can compensate for poor quality in education in terms of improving staff performance.
\end{abstract}

Keywords: Effective Training, Human Resources Development, Training Transfer, University Personnel

\section{Introduction}

The staff is the strategic resource of the organization ${ }^{1}$. Today, the successful development of the economy is driven by human resources $\frac{2,3}{3}$. Human resource is the most valuable aspect of all resources of the organization ${ }^{4}$.

Training is the most common form of human resource development and the one that helps organisations to enhance workforce effectiveness and productivity the most $\frac{5-7}{b y}$ means of specified learning geared towards performance improvement. Training is appropriate when an individual's performance would be improved with additional skills and knowledge ${ }^{8}$. Employees and organisations can achieve their aims if training skills are transferred to the work environment $\stackrel{9}{\text {. Training focuses }}$ on changing the behaviour or to develop new skills and knowledge for individual trainees and is expected to be applied in the workplace. Training Transfer is defined as the degree to which trainees generalise and apply knowledge, skills, and abilities to their jobs ${ }^{10}$. There are many studies that have examined the transfer of training $\frac{11-20}{}$. Previous studies have identified many factors that affect the transfer of training. These studies distinguish three categories of factors affecting training transfer at work:

- Trainee characteristics;

- Training design factors; and

- Environmental factors.

But, this stream of research has been very limited in Iran and a serious attempt has been not made to identify factors affecting the transfer of training. Considering such problem, planning for development of transfer of training is still an essential requirement in Medical Universities

${ }^{*}$ Author for correspondence 
of Iran as starting point. Therefore, the purpose of this study was to identify and examine the factors affecting the transfer of training among human resources of Medical Science Universities of Iran in the period of 2015 - 2016.

\section{Theorical Framework}

\subsection{Transfer of Training}

Training transfer is one of the most important ways for improving the effectiveness, productivity and improving knowledge and skills of employees in dealing with the challenges of the workplace.

Training transfer defined as trainees effectively and continually applying the knowledge, skills, behaviours and cognitive strategies to the workplace ${ }^{21}$. Transfer of training attributes to the grade of trainees who apply knowledge, skills, behaviours and attitudes into their workplace after training that requires a generalisation of training to their job setting and its perseverance over time to improve their job performance $e^{11,22}$.

\subsection{Factors Influencing Transfer of Training}

There are numerous researches in the field of training transfer to try and gain a better understanding of the fac-

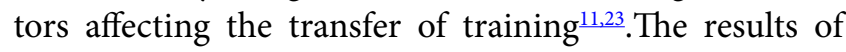
research conducted by Baldwin and Ford ${ }^{11}$ has shown that the transfer of training is divided into three categories: trainees' characteristics (or individual factors), training design, and the work environment (or environmental factors). These results have been accepted by researchers that these factors deeply influenced the training transfer ${ }^{24}$.

\subsubsection{Trainee's Characteristics}

Researchershave shown that the trainees' characteristics directly affect the transferof training and training process $^{25}$. Some of these characteristics include achievement motivation, the locus of control, anxiety, cognitive ability, self-efficacy, conscientiousness, motivation to learn and to transfer, and valence ${ }^{12}$. Others include job involvement, job satisfaction, organisational cynicism, and organisational commitment ${ }^{22}$.

Also, the transfer research indicates that motivation to transfer, self-efficacy, and personality, in particular, influence transfer of training directly or indirectly $\underline{12,14,15}$,

26. Learners' readiness, and motivation to attend training and to transfer training and personal physical and cogni- tive capacity to transfer training were found to positively influence the transfer of training $\underline{14,27}$.

\subsubsection{Training Design}

The second group of variables that have a direct or indirect impact on training transfer through their influence on learning includes training design and delivery. Training design often referred to the degree of training is to provide instruction on how to transfer knowledge and skills to the job ${ }^{26}$. Holton, et al ${ }^{27,28}$ stresses that for effective transfer design, the training must match the job requirements.

Researchersindicatethat training design influences training transfer ${ }^{29,30}$; that is, when staffs understand how to use the knowledge and skills learned once back on the job, they are more likely to engage in successful transfer ${ }^{31}$. Training design also influences performance self-efficacy and transfer motivation ${ }^{32}$. If the effectiveness of transfer is a positive change in individual performance, then the design and training transfer must correspond as directly as possible with the work environment and job requirements $s^{30,32}$.

\subsubsection{Environmental Factors}

The environmental factors has been the subject of many empirical organizational-training studies. The emerging perspective of training transfer recognises training as a complex process and multifaceted that can be influenced by factors within the workplace $e^{28,29}$.

Researchershasindicated that training efforts are unlikely to result in positive changes in job performance unless the newly trained skills are transferred to the work environment ${ }^{20}$. Also, researcheshas supported the importance of the environment on the trainee's ability to apply, maintain, and generalise new competences on the job $11 \underline{128,29}$.

Indeed, work environment factors refer to the way workers perceive the supportiveness of their organisation's policies towards training, supportiveness of the supervisors and fellow workers, available opportunities to perform, and the adequacy of resources within the work-

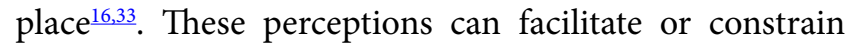
transfer of training to the workplace.

\section{Methodology}

A mixed method research design was utilised. The study population was the employees of Universities of 
Medical Science, in western provinces of Iran. First, 17 experts were interviewed. Second, relying on interviews, a questionnaire was developed it among the universities employees.

In this study (In qualitative research phase), the first tool for collecting data was a semi-structured interview. The Thematic Content Analysis (TCA) technique was selected as an analytical method for qualitative research.

In quantitative research phase, the second tool was the questionnaire developed based on the interviews consisting of 100 items. Cronbach (a) calculated for the questionnaire was 0.93 and it showed a fair reliability. Exploratory Factor Analysis (EFA) showed extraction of six factors (see detailed information in the section of results).

In quantitative research phase of the research, the study population included 2912 universities personnel from which a sample of 346 was randomly selected. The sample consisted of 107 male employees (30.9 percent) and 239 female employees (69.1 percent). The average age of the respondents was 38.7 years (ranging from 24 to 55 years). The Average length of service for teachers was 13.3 years. With regard to professional qualification, 22.3 percent had an Associate's Degree, 46.2 percent had a Bachelor's degree and 31.5 percent had a master's degree.

\section{Results}

\subsection{Dimensions of Transfer of Training}

The main objective of this study was to explore basic dimensions of training transfer among human resources of universities of medical science of Iran. In the first phase, analysing the interview data indicated the following factors:

- Factors concerning the planning of the training (Training design);

- Factors concerning the trainee (Individual factors);

- Supportive factors affecting the transfer of training (Supportive factors);

- Management factors affecting the transfer of training (Management factors);

- Cultural factors affecting the transfer of training (Cultural factors); and

- Environmental factors affecting the transfer of training (Environmental factors).

\subsection{Exploratory Factor Analysis}

An exploratory factor analysis was performed to explore factor structure based on the initial form of transfer of training with 100 items. Varimax rotation method was utilised as well as principal components was approved to scores obtained associated with answers given by 346 employees to determine the scale factor structure. The $\mathrm{KMO}$ index was found to be 0.82 which is considered suitable for exploratory factor analysis.

Another indicator of the strength of the relationship among variables is Bartlett's test of sphercity and should be significant $(\mathrm{p}<0.05)$ for factor analysis to be suitable. In this study, the observed significance level was $\mathrm{p}<0.0001$.

Table 1. Structural factors model and reliability of each factor using IBM SPSS and Amos 23

\begin{tabular}{|l|l|l|l|}
\hline & Eigenvalues & $\begin{array}{l}\text { Variance of } \\
\text { factors (\%) }\end{array}$ & $\begin{array}{l}\text { Cronbach's } \\
\text { alpha }\end{array}$ \\
\hline $\begin{array}{l}\text { Training design } \\
\text { factors }\end{array}$ & 32.48 & 34.56 & 0.93 \\
\hline $\begin{array}{l}\text { Management } \\
\text { factors }\end{array}$ & 8.25 & 8.78 & 0.90 \\
\hline $\begin{array}{l}\text { Environmental } \\
\text { factors }\end{array}$ & 5.32 & 5.66 & 0.91 \\
\hline Cultural factors & 4.21 & 4.49 & 0.92 \\
\hline $\begin{array}{l}\text { Supportive } \\
\text { factors }\end{array}$ & 3.53 & 3.76 & 0.92 \\
\hline $\begin{array}{l}\text { Individual } \\
\text { factors }\end{array}$ & 1.40 & 3.62 & 0.92 \\
\hline $\begin{array}{l}\text { Transfer of } \\
\text { Training (TT) }\end{array}$ & & 60.87 & 0.93 \\
\hline
\end{tabular}

EFA on the training transfer extracted 7 factors with eigenvalues exceeding 1.0 and represented the variance explained $64.301 \%$ as a result. Scree plot was shown that six factors were in sharp descent and then started to level off. Generally, 6 of 7 factors were indicated just by one item per each factor with loading higher than 0.4. Thus, the factor analysis represented in 6 independent factors with factor loadings more than 0.4 .

This model explained $60.878 \%$ out of total variance. Moreover, one item (Q12) had no suitable factor loading and five items (Q18, Q19, Q47, Q48, and Q49) had cross load over factors, thus they were not considered in further data analysis. Finally, factors were named based on face validity, logical and conceptual relationship among items, and results of qualitative: "training design" (32.48\% out 
of total model variance), "Management factors" (8.25\%), "Environmental factors" (5.32\%), "Cultural factors" (4.21\%), "Supportive factors" (3.53\%), "Individual factors" (3.40\%). Table 1 gives the eigenvalues, total variance explained and factors.

Reliability analysis for each factor was performed through SPSS (ver23). Sufficient results are revealed by each analysis. In another word, the sufficiency of Cronbach's Alpha Reliability Coefficient $(\alpha)$ was clarified as well as the overall reliability of variables measured by Cronbach's Alpha equals 0.93 .

Correlations of all 6 factors have a significant P-value smaller than 0.0001 . Also, it is an exhibition of those factors having factor loading more than 0.4. Above results show high levels of internal consistency ${ }^{34,35}$ indicating good construct reliability and adequate convergent validity.

\section{Discussion and Conclusion}

The main purpose of this study was to identify, describe and examine factors that affect the transfer of training among Human Resources of Universities of Medical Science in Iran. This study showed that employees determined six fundamental factors that affect the transfer of training in Iran's Universities of Medical Science: Training design factors, Management factors, Environmental factors, Cultural factors, Supportive factors, Individual factors.

\subsection{Training Design}

The results of this research that indicate the need assessment, goal setting, considering the time required to do the job, content relevance significantly affects the transfer of training within the training design. The results also demonstrate that active learning, practice and feedback, behaviouralmodelling, error-based examples and self-management strategies variables as training design and delivery factors that were used in the training transfer within the training design. Therefore, these results reinforce the notion that universities should be aware of how well the content of the training programs, in terms of the need assessment, goal setting, active learning and self-management strategies, is focused on the application of training.

The main components related to training success include the quality of instruction, the content of training, and training design ${ }^{36,37}$.Also, the results are consistent with the findings found by Lim and Johnson ${ }^{38}$, who state that content, training design, and instructional strategies must be related to the training transfer, whether near or far transfer, for training transfer to be realised. Indeed, transfer design develops understanding about the training program and shows a practical way in which training can be best used in the workplace.

\subsection{Management Factors}

It was found in this study that management factors play a role in the ability of staff to training transfer. Based on the study, the management factors which influence in training process are an accurate evaluation of employee's performance, reward, and feedback.

Axtell et al. $\frac{39}{\text { found }}$ that staffs with supportive managers are more likely to implement what they have learned. Also, this study indicated that a relationship does exist between training transfer, feedback and reward. Reward and incentive systems necessary for continued transfer $\underline{44,40}$. Myers ${ }^{41}$ showed that performance coaching, reward and feedback and positively affected training transfer.

\subsection{Environmental Factors}

The results of this research demonstrate that the opportunity to use and equipment availability significantly affects the transfer of training within the work environment. Lance et al. $\stackrel{42}{ }$ have shown that work environment factors are critical for understanding the training transfer process. Previous researchers indicate that environmental factors affect training transfer $\frac{43,44}{3}$.

In past research studies $\frac{11,45,46}{}$, various environmental factors have been showed which, when applied well, facilitated the transfer of training back in the workplace. Work environment factors include an opportunity to perform or use training ${ }^{\frac{47}{7}}$; technological support $\frac{48}{4}$; tools available on the job, availability of a mentor ${ }^{49}$.

Kupritz $^{50}$ and Gilpin-Jackson and Busche ${ }^{51}$ emphasised the importance of contexts to transfer of training. According to May and Kahnweiler ${ }^{52}$ trainers should provide opportunities to performance, in order to show the trainee the practical relevance of the training programs and to ensure training transfer. When staffs do not have opportunities to performance trained knowledge and skills, skills decay may occur, making the transfer of training difficult.

\subsection{Cultural Factors}

The results of this study indicate the importance of organisational culture and the influence of the environmental 
factors on the training transfer. This study also indicates that organisational culture, assessed by how applicable the training was to the workplace, influenced the training transfer.

According to Elangovan A, Karakowsky ${ }^{43}$, an organisational culture positively influences training transfer. Gilpin-Jackson and Busche $\mathrm{e}^{\underline{1}}$ and Nikandrouet al. $\underline{53}$ showed that organisational culture may hinder transfer or facilitate of training, depending on whether the culture is supportive of training initiatives and new routes of working. Previous researchers have also found that organisational cultures and subcultures influence training transfer ${ }^{\frac{54}{4}}$. For instance, Tracey et al., $\frac{55}{\text { and Hofstede }}{ }^{\frac{56}{}}$, showed that a culture of learning positively influences training transfer.

Therefore, this study reinforced the point that universities should be aware of how well the content of the organisational culture, in terms of the use of examples, activities, and exercises, is focused on the application of onthe-work learning. Based on this study, the cultural factors which influence in training process are learning culture, organisational learning, and cultural appropriateness.

\subsection{Supportive Factors}

In this study, respondents highlighted the role of the supervisor in the transfer of training to the workplace. Participants also indicated that "supervisors just do not have interest" on the development and growth of staffs.

Supervisors play an important role in transfer process $^{57}$. Previous studies indicate that supervisor support influences transfer of training directly ${ }^{51,58,59}$. Supervisor support refers to "the extent to which supervisors support and reinforce the use of training on the job" $\underline{\text { "29 }}$. Also, Kirwan ${ }^{60}$ showed the role of supervisors as a mentor, coach, advocate for an organisation and advocate for a staff.

In summary, the organisational factor that can strongly interfere with a transfer is the organisational support for the transfer of training. It is a broad factor that includes the various strategies that a company or institution displays with regards to facilitating the transfer, and which are determined according to the consideration given by the organisation to transfer.

\subsection{Individual Factors}

The trainee's performance after learning is one of the elements of the effectiveness of the training transfer. Based on this study, the trainee characteristics which influence in transferring process are motivation to learn and to transfer, self-efficacy and cognitive ability. Also, organisational commitment, job involvement, and job satisfaction are trainee's characteristics stated by the examinees. These findings are consistent with those of other researchers ${ }^{11}, 22$, which found significant positive relationships between the dimensions of trainee characteristics and job training transfer.

The literature on training transfer has identified several trainee characteristics that affect the training transfer. These characteristics include motivation to transfer, anxiety, cognitive ability, conscientiousness and self-efficacy ${ }^{11}$, organisational commitment, job involvement, organisational cynicism and job satisfaction 22 .

\section{Implication and Recommendations}

\subsection{Recommendations for Future Research}

- This study point to six factor. Further research may explore more factors affecting the training transfer to the job.

- The findings of this study should be investigated further with a different population.

- A longitudinal study of training effectiveness should be conducted to determine whether the trainees maintained the learned competence during a time.

- Future studies may want to consider collecting data on such variables as age and gender.

- This study could be redesigned to include a control group and an experimental group.

\subsection{Recommendations for Practitioners}

Based on the findings of this research, the recommendations provided below might be considered by any training or management professional who wants to improve the success of training programs.

- It is recommended that for trainees to maintain the use of newly learned skills and transfer them to the job, a monitoring system needs to be developed where an experienced supervisor coaches, supports and encourages the new trainees to implement their knowledge and skills. 
- The training program should be based on a needs assessment. Upon analysis of the need assessment data, appropriate instructional strategies need to be selected prior to delivering the training program. It also should be pilot tested and modified as appropriate and continually evaluated periodically and updated accordingly.

- It is proposed that there should be a follow-up of training periodically.

\section{References}

1. Morozova LS, Morozov VY, Khavanova NV, Lustina TN, Panova AG. Approach to Evaluating Personnel Loyalty in the Context of Streamlining the Company's Human Resources Policy. Indian Journal of Science and Technology. 2016 Mar 29; 9(12): Crossref.

2. Lang T, Gupta B. The human resource issues and their impact on firm growth in small e-businesses in China. Indian Journal of Science and Technology. 2015 Feb 1;8(S4):135-44. Crossref

3. Sayadi S, Bigdelimojarad B. Identify and Prioritize Effective Factors on Establishment of Electronic Human Resource Management through Fuzzy Hierarchical Analysis Approach (Case Study: Unit 7 of Iran Gas Transfer Operation). Indian Journal of Science and Technology.2015Oct1; 8(28):1. Crossref

4. Das PN, Nayak B. Measuring the Effectiveness of Human Resource Planning: A Case of NilachalIspat Nigam Limited. Indian Journal of Science and Technology. 2015 Dec 20: 8(35). Crossref

5. Yamnill S, McLean GN. Theories supporting transfer of training. Human resource development quarterly. 2001;12(2):195-208. Crossref

6. Pineda P. Evaluation of training in organizations: a proposal for an integrated model. Journal of European Industrial Training. 2010;34(7):673-93. Crossref

7. Bhatti MA, Kaur S, editors. Factors effecting transfer of training: a fresh review. 12th International Business Information Management Conference (IBIMA), Kuala Lumpur; 2009.

8. Berge ZL. Why it is so hard to evaluate training in the workplace. Industrial and Commercial Training. 2008;40(7):390-5. Crossref

9. Bhatti MA, Kaur S. The role of individual and training design factors on training transfer. Journal of European Industrial Training. 2010; 34(7):656-72. Crossref

10. Park JH, Wentling T. Factors associated with transfer of training in workplace e-learning. Journal of Workplace Learning. 2007;19(5):311-29. Crossref
11. Baldwin TT, Ford JK. Transfer of training: A review and directions for future research. Personnel psychology. 1988;41(1):63-105. Crossref

12. Kontoghiorghes C. Reconceptualizing the learning transfer conceptual framework: Empirical validation of a new systemic model. International journal of training and development. 2004;8(3):210-21. Crossref

13. Aguinis $H$, Kraiger K. Benefits of training and development for individuals and teams, organizations, and society. Annual review of psychology. 2009;60:451-74. Crossref PMid:18976113

14. Burke LA, Hutchins HM. Training transfer: An integrative literature review. Human resource development review. 2007;6(3):263-96. Crossref

15. Cheng EW, Ho DC. A review of transfer of training studies in the past decade. Personnel review. 2001;30(1):102-18. Crossref

16. Grossman R, Salas E. The transfer of training: what really matters. International Journal of Training and Development. 2011; 15(2):103-20. Crossref

17. Kozlowski SW, Salas E. Learning, training, and development in organizations: Taylor \& Francis; 2009.

18. Salas E, Cannon-Bowers JA. The science of training: A decade of progress. Annual review of psychology. 2001; 52(1):471-99. Crossref PMid:11148314

19. Salas E, Tannenbaum SI, Kraiger K, Smith-Jentsch KA. The science of training and development in organizations: What matters in practice Psychological science in the public interest. 2012;13(2):74-101. Crossref PMid:26173283

20. Salas E, Weaver SJ, Shuffler ML. Learning, training, and development in organizations. The Oxford handbook of organizational psychology. 2012; 1:330-72. Crossref

21. Noe RA. Employee training and development: McGrawHill/Irwin; 2010.

22. Velada R, Caetano A. Training transfer: the mediating role of perception of learning. Journal of European Industrial Training. 2007;31(4):283-96. Crossref

23. Lim DH, Morris ML. Influence of trainee characteristics, instructional satisfaction, and organizational climate on perceived learning and training transfer. Human Resource Development Quarterly. 2006; 17(1):85-115. Crossref

24. Nazli NNNN, Sipon S, Zumrah AR, Abdullah S. The Factors That Influence The Transfer Of Training In Disaster Preparedness Training: A Review. Procedia-Social and Behavioral Sciences. 2015; 192:54-8. Crossref

25. Warr P, Allan C, Birdi K. Predicting three levels of training outcome. Journal of Occupational and Organizational Psychology. 1999; 72(3):351-75. Crossref

26. Cheng EW, Hampson I. Transfer of training: A review and new insights. International Journal of Management Reviews. 2008; 10(4):327-41. Crossref 
27. Devos C, Dumay X, Bonami M, Bates R, Holton E. The Learning Transfer System Inventory (LTSI) translated into French: internal structure and predictive validity. International Journal of Training and Development. 2007;11(3):181-99. Crossref

28. Holton EF. The flawed four-level evaluation model. Human resource development quarterly. 1996; 7(1):5-21. Crossref

29. Velada R, Caetano A, Michel JW, Lyons BD, Kavanagh MJ. The effects of training design, individual characteristics and work environment on transfer of training. International Journal of Training and Development. 2007;11(4):282-94. Crossref

30. Kirwan C, Birchall D. Transfer of learning from management development programs: testing the Holton model. International Journal of Training and Development. 2006;10(4):252-68. Crossref

31. Holton EF, Bates RA, Ruona WE. Development of a generalized learning transfer system inventory. Human resource development quarterly. 2000; 11(4):333-60. Crossref

32. Holton EF. Holton's evaluation model: New evidence and construct elaborations. Advances in developing human resources. 2005; 7(1):37-54. Crossref

33. Chiaburu DS. The social context of training: coworker, supervisor, or organizational support? Industrial and commercial training. 2010;42(1):53-6. Crossref

34. Ugulu I. Confirmatory factor analysis for testing validity and reliability of traditional knowledge scale to measure university students' attitudes. Educational Research and Reviews. 2013; 8(16):1399.

35. Said H, Badru BB, Shahid M. Confirmatory factor analysis (CFA) for testing validity and reliability instrument in the study of education. Australian Journal of Basic and Applied Sciences. 2011; 5(12):1098-103.

36. Saks AM, Salas E, Lewis P. The transfer of training. International Journal of Training and Development. 2014;18(2):81-3. Crossref

37. Bouzguenda K. Enablers and inhibitors of learning transfer from theory to practice. Transfer of learning in organizations: Springer; 2014. p. 23-44.

38. Lim DH, Johnson SD. Trainee perceptions of factors that influence learning transfer. International journal of training and development. 2002;6(1):36-48. Crossref

39. Axtell CM, Holman DJ, Unsworth KL, Wall TD, Waterson PE, Harrington E. Shopfloor innovation: Facilitating the suggestion and implementation of ideas. Journal of occupational and organizational psychology. 2000; 73(3):265-85. Crossref

40. Machin MA. Planning, managing, and optimizing transfer of training. Creating, implementing, and managing effective training and development. 2002:263-301.

41. Myers MJM. Transfer of learning from training program to the workplace in a university healthcare organization setting. 2009.
42. Lance CE, Kavanagh MJ, Brink KE. Retraining climate as a predictor of retraining success and as a moderator of the relationship between cross-job retraining time estimates and time to proficiency in the new job. Group \& Organization Management. 2002; 27(2):294-317. Crossref

43. Elangovan A, Karakowsky L. The role of trainee and environmental factors in transfer of training: An exploratory framework. Leadership \& Organization Development Journal. 1999; 20(5):268-76. Crossref

44. Lim DH. The Effect of Training Design, Work Environment, and Cultural Factors of the Transfer of Training for Korean HRD Professionals: the University of Illinois at UrbanaChampaign; 1998.

45. Ford JK, Qui-ones MA, Sego DJ, Sorra JS. Factors affecting the opportunity to perform trained tasks on the job. Personnel psychology. 1992;45(3):511-27. Crossref

46. Stevens G, Stevens E. The truth about EPSS. Training \& Development. 1996; 50(6):59-61.

47. Richey RC. The Effects of Organizational Climate Factors on Industrial Training Outcomes. 1990.

48. Helfat CE, Peteraf MA. The dynamic resource-based view: Capability lifecycles. Strategic management journal. 2003; 24(10):997-1010. Crossref

49. Scott L. A Study on the Relationship between Ability, Motivational, and Work Environmental Influences and the Degree of Transfer of Learning of New Trainers: ERIC; 2010.

50. Kupritz VW. The relative impact of workplace design on training transfer. Human resource development quarterly. 2002; 13(4):427-47. Crossref

51. Gilpin-Jackson Y, Bushe GR. Leadership development training transfer: A case study of post-training determinants. Journal of management development. 2007; 26(10):980-1004. Crossref

52. May GL, Kahnweiler WM. The effect of a mastery practice design on learning and transfer in behavior modeling training. Personnel Psychology. 2000; 53(2):353-73. Crossref

53. Nikandrou I, Brinia V, Bereri E. Trainee perceptions of training transfer: An empirical analysis. Journal of European Industrial Training. 2009; 33(3):255-70. Crossref

54. Egan TM. The relevance of organizational subculture for motivation to transfer learning. Human Resource Development Quarterly. 2008;19(4):299-322. Crossref

55. Tracey JB, Tannenbaum SI, Kavanagh MJ. Applying trained skills on the job: The importance of the work environment. Journal of applied psychology. 1995; 80(2):239. Crossref

56. Hofstede G. Identifying organizational subcultures: An empirical approach. Journal of management studies. 1998; 35(1):1-12. Crossref

57. Martin HJ. Improving training impact through effective follow-up: Techniques and their application. Journal of Management Development. 2010;29(6):520-34. Crossref 
58. Austin MJ, Weisner S, Schrandt E, Glezos-Bell S, Murtaza N. Exploring the transfer of learning from an executive development program for human services managers. Administration in Social Work. 2006; 30(2):71-90. Crossref

59. Saks AM, Belcourt M. An investigation of training activities and transfer of training in organizations. Human resource management. 2006;45(4):629-48. Crossref
60. Kirwan C. Improving learning transfer: A guide to getting more out of what you put into your training: Gower Publishing,Ltd.;2009. 